\title{
A Poisoned Chalice: Impact of Introducing a Store on Social Media Fan Pages on Customer Engagement and Product Sales
}

\author{
Shuting Ada Wang \\ Temple University \\ ada.wang@temple.edu
}

\author{
Sunil Wattal \\ Temple University \\ swattal@temple.edu
}

\begin{abstract}
While social media fan pages are being widely used by firms, their value in terms of influencing customer behavior is not clear. In this study, we examine the impact of introducing "stores" on social media fan pages on customer engagement and purchase. Using a unique dataset from a fashion retailer, we find that opening a fan page store can lead to negative outcomes for the firm. Our results suggest that introducing a fan page store significantly reduces customer engagement with the fan page by $26 \%$. More importantly, results indicate that introducing a fan page store decreases the retailer's sales by $4.6 \%$. The study informs managerial practice on whether to leverage fan page stores for enhancing customer engagement and promoting sales.
\end{abstract}

\section{Introduction}

From the weblog culture of the late 1990 s, to the Facebook surge in the early 2000s, firms have leveraged social media to tailor their messages to customers, encourage customer engagement, and increase brand-customer relationship; all in an effort to drive sales at lower marketing costs $[35,39]$. One of the recent trends in this area is the use of social media fan pages (viz. those on Facebook, Pinterest, and our focal platform WeChat) by firms. Some practitioners utilize fan pages as an extension of the traditional mass media, directly posting product images, prices and promotions to promote sales [35]. However, it is likely that commercializing fan pages may annoy social media users and drive away potential buyers. Some scholars argue that firms should respect the "social" characteristics of fan pages and focus on their value in developing long-term customer relationships [10, 25]. A lack of understanding regarding the benefits and potential drawbacks of monetizing the fan pages makes many executives ignore or mismanage the opportunities and threats presented by social media.
Nevertheless, despite concerns about the potential negative effects, firms' desire to leverage social media fan pages and the profit motive of social media platforms have pushed these fan pages towards greater commercialization. For example, Facebook introduced a shop section that allows firms to display and sell products on their fan pages. Though Facebook claims that "It's ideal for merchants, retail and eCommerce advertisers who want to reach customers on Facebook", many retail giants, such as Gap, J.C. Penney, Nordstrom and GameStop, have all closed their shops on Facebook within one year of opening. ${ }^{1}$ Such failures do not deny the potential of social media as sales channels, but highlight the necessity to uncover the mechanism of how introducing a store on fan pages may influence firms.

Selling through social media pages may seem an ideal way for firms to monetize their connections with customers in social networks, but the relation is more complicated in the real world. Firstly, social media platforms such as Facebook and WeChat are primarily designed for social activities, and are at a disadvantage compared to e-commerce platforms such as Amazon which are primarily designed for sales. Secondly, social media are private spaces, and social media users may feel uncomfortable about firms' sales pitch on their private territories. The boundary regulation theory indicates that pure selling on social media may violate people's privacy boundary on social media, thus eliciting negative attitudes [22, 36]. This negative perception may cause customers to engage less with the fan page, and lead to lower sales for the firm [20]. Since introducing stores on fan pages is new in practice, the net impact has not been investigated and firms lack the knowledge on how to fully leverage the potential value of fan page stores. Inspired by the gap in the literature and practice, we explore the impact of fan page stores by investigating two research questions:

\footnotetext{
${ }^{1}$ https://www.bloomberg.com/news/articles/2012-02-17/fcommerce-trips-as-gap-to-penney-shut-facebook-stores-retail
} 
- how does introducing a store on social media fan pages impact customer engagement with the fan page?

- how does introducing a store on social media fan pages impact customer purchases?

To examine these research questions, we leverage a dataset from a leading fashion retailer in China. We selected the top shoe brand operated by this retailer and collected data over a two-year time window (from May 2015 to May 2017). The dataset contains customers' demographics and weblogs of customers' actions on the brand's fan page as well as their purchase history. The dataset is unique in several ways: firstly, this retailer maintains a fan page for each brand on WeChat---a leading social media platform in China, and introduced "stores" on its fan pages in June 2016. While the fan pages provide social content for products/brands, a fan page "store" mainly focuses on selling by displaying pictures of products, real-time prices, amount of sales/inventory, and discounts. Secondly, this retailer maintains a loyalty program, which assigns a unique member ID to each customer. The loyalty system gives registered members an additional 5\% discount for all purchases, thereby incentivizing customers to participate in it. Data show that more than $70 \%$ of all sales are recorded in the loyalty system. Thirdly, we collect data with a field experiment, in which we have a control group--Beijing where the fan page store was not available for the period of our data collection and a treatment group--Shenzhen where the fan page store was available to customers at roughly the midway point during our data collection period. After validating the parallel trend assumption between the control and the treatment group, we employ a difference-in-difference method to test how the introduction of the fan page store may influence customer engagement and purchase.

Our study has several notable findings. Firstly, we find that, the introduction of a fan page store significantly decreases customer engagement with the fan page. Economically, after the introduction of the fan page store, the probability of customers' daily engagement with the fan page decreases on average by $26 \%$. Second, we find that the introduction of a fan page store significantly decreases total sales. In economic terms, after the introduction of the fan page store, customers are, on average, $4.6 \%$ less likely to make a purchase.

Our study makes several contributions to literature. First, we consider a novel context that has received limited consideration from information systems researchers. Though scholars have studied the business value of social media fan pages $[2,15,18,33]$, this study, to the best of our knowledge, is the first to concomitantly test the impact of the introduction of a fan page store. Second, we contribute to the literature about product information disclosure [13, 27, 28], by exploring how disclosing product information on fan page stores may affect customer engagement. Our finding of a negative impact of the fan page store on online engagement uncovers the mechanism how a fan page store might hurt firms' benefits. Third, our study is the first to measure the economic influence of a fan page store on sales. Our finding of a decrease in product sales after introducing the fan page store, informs both academics and practitioners to the potential risks of over-commercializing social media fan pages.

\section{Theory and hypotheses}

\subsection{Fan page stores and customer engagement}

In this section, we discuss literature on social media and boundary regulation theory to investigate how the introduction of a fan page store may influence customer engagement with the fan pages.

Prior work on social media has put forth two main reasons for why people engage with fan pages [7, 17, 23, 37]. Firstly, people engage with fan pages for seeking information to indulge in entertainment, price comparison, deal seeking, and assortment seeking [16]. Heller Baird and Parasnis [16] believe people will engage with brands in their social space when their desires for extra information outweigh their privacy concerns. Secondly, people engage with fan pages to express themselves or communicate with others in the same community $[19,31]$. On fan pages, people can publicize their evaluations of brands/products, write reviews and comments, and communicate with other individuals interested in the same brands. In this case, customers are actually in control of communication and firms are expected to act as "listeners". Considering that fan page stores only enable firms to list information (such as products details and prices) which are already available on firms' regular ecommerce websites, introducing fan page stores may hardly drive product information seeking on fan pages. Besides, fan page stores are not designed for customer communication, and therefore will have no impact on customer communication experiences and satisfactions on fan pages. From this aspect, fan page stores may hardly attract more customer engagement

Furthermore, the boundary regulation theory indicates that introducing a store on fan pages may violate people's privacy boundary on social media, thus eliciting negative attitudes and undermining their willingness to engage with the fan page $[36,40]$. Social media pages are private spaces where people share personal information and keep in touch with families 
and friends [21, 23]. To protect privacy, people regulate their territories on social media through the mechanism of interaction boundary regulation, in which they manage their informational and interactional privacy by controlling boundaries for incoming and outgoing content and interaction [21]. Boundaries are important, and they give people a sense of safety (physically and emotionally) [9]. On social media, people regulate boundaries for relationships and networks to regulate their privacy levels [40]. For example, many people never engage with businesses via social media sites. For them, social media is a place for social activity, and interacting with business on their social space leads to privacy concerns [16]. Such desire to protect privacy elicits people's will to control their interaction boundaries, eliciting resistance to directly engage with businesses on social media. Empirical studies also show that information about pure selling (such as prices, availability, and product features) reduces customer engagement on social networks [26]. In the context of fan pages, when firms introduce a store on fan pages, the business feature of fan pages will be amplified. When such business feature of fan pages conflicts with people's definition of privacy or interaction boundaries on social media, people are likely to act to limit the incoming flow of the business appearance to their private spaces, by ignoring the fan pages to regulate the information boundary or unfollowing the fan pages to regulate the relationship boundary. All these actions would reduce customer engagement with the fan page. Therefore, we propose the following hypothesis:

Hypothesis 1: The introduction of a fan page store will be negatively associated with customer engagement with the fan page.

\subsection{Fan page stores and customer purchases}

In this section, we juxtapose the studies on online product exposure and literature on customer engagement to investigate the impact of fan page stores on purchases $[6,17]$.

Prior research in marketing suggests that online product exposure could increase customer purchases in the short term by creating immediate brand awareness, instantly framing customer previous usage experience, inducing trial, and facilitating repeat purchases $[5,8$, $12,29,32]$. In the context of fan pages, firms actively send messages to followers. Usually, firms do not post direct information for selling on fan page. Instead, they provide product/brand content relevant to customers. For example, firms may post information about an event that customers can participate in or a news article related to the brand. When a customer engages with fan pages, she will be exposed to those posts, therefore obtaining a rudimentary level of brand and product knowledge and forming purchase preferences. However, if the introduction of fan page stores reduces customer engagement with the fan page, firms would have less chance to expose products among customers and lose sales.

Prior literature on customer engagement suggests that customer engagement itself also helps develop consumer loyalty and increases sales in the long term $[16,24,34]$. For example, Rishika et al. [33] found that customers' engagement with brands on Facebook could create the feeling of a brand/firm community and positively influence customers' intensity of relationship with the firm. The influence of customer voluntary engagement could be totally different from the effect of firms' active efforts in exposing products to customers. Customer engagement are usually initiated when customers value brand posts as an information source or a means to express their opinions about the brand $[10,16]$. In that case, customers could benefit from such interactions and enjoy good experience with the focal brands. From this aspect, if the introduction of fan page stores reduces customer engagement with the fan page, it is likely to hurt firms' ability to enhance customer experience and loyalty through fan pages, thereby lowering customer purchases in the long run. We therefore propose the following hypothesis:

Hypothesis 2: The introduction of a fan page store will be negatively associated with customer purchases.

\section{Context and data}

To empirically estimate the impact of the introduction of fan page stores, we leveraged a dataset from a leading fashion retailer in China. The retailer mainly sells shoes in China through brick and mortar stores, with $\$ 3.5$ billion revenue in 2015 . The social media platform we discussed in this paper is WeChat, a leading mobile social media app in China, with more than 846 million active users in the world. The fashion retailer represents an ideal context for our study for several reasons.

First, the retailer establishes one fan page for each brand on WeChat, and introduced a fan page store on the fan page in 2016. Previously, the retailer only presented general information about product/brand personality on the fan page. In July 2016, the retailer wanted to increase product exposure and added a new feature of "store" on the fan page. Graphic display of the "store" is exhibited in Figure 1. In the "store", the retailer lists pictures of products on the market, real- 
time prices, discounts, and information about sales/inventory.

Second, we are able to track each individual's purchase history. The retailer holds a loyalty program, which records each member's purchase over time ${ }^{2}$. Importantly, the loyalty system gives all registered members a unique member ID. The unique member ID, usually generated based on phone numbers, enables us to track each member's purchase over time. More importantly, we are therefore able to merge purchase data with online action data at an individual level. Besides, the retailer offers an additional 5\% discount for all purchase to incentivize customers to participate. As a result, data indicates that the loyalty program captures more than $70 \%$ of the retailer's total sales.

Third, we collect data using a field experiment by selecting different cities for our control group and treatment group. To test the influence of fan page stores, the retailer selected Shenzhen (Head Office City) as the treatment city. It implemented the "store" section into its fan page in July 2016, and made it only visible to WeChat users located in Shenzhen. We use customers in Shenzhen as the treatment group. Considering the population size of the customer base, we select another big city---Beijing which is similar to Shenzhen in terms of economic and demographic composition---as the control group. A difference-indifference approach would help to test how the introduction of a fan page store may influence customer engagements and purchase behavior.

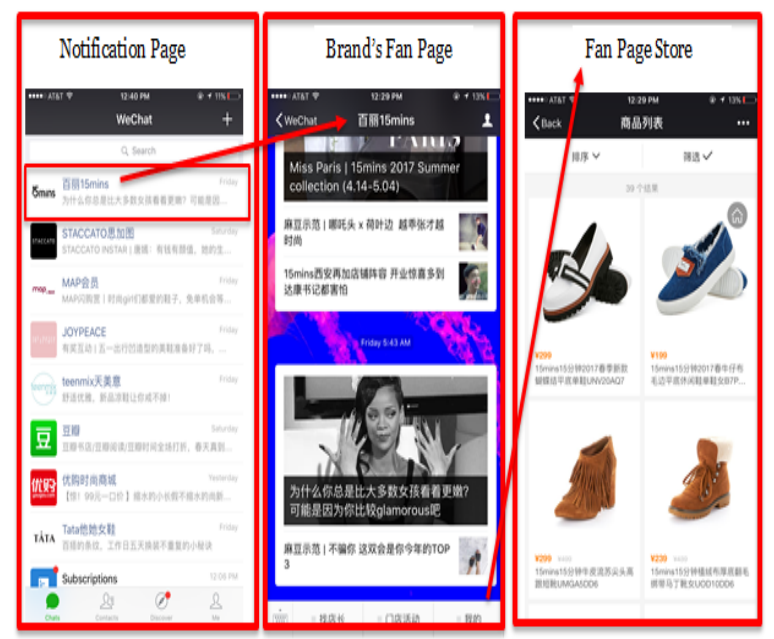

Figure 1. Exhibition of the notification page, the fan page, and the fan page store on Wechat

\footnotetext{
2 Since the loyalty system only works in offline stores, we only have data for customers' offline purchase. However, as $92 \%$ of the retailer's total sales come from traditional stores, we should be able to capture the major share of the effect.
}

We further apply two restrictions to the data sets. First, considering the population size of the consumer base, we focus on the top $10 \%$ customers who actively engage with the fan page before the introduction of the fan page store in both Shenzhen and Beijing. Such strategy helps us focus on the subjects most likely to be influenced. Second, for merging purchase and online action data with member IDs in the loyalty program, we removed the data for individuals if they never logged into their loyalty accounts through the fan page before the time we collected the data (May 2017). With these restrictions, we have a total of 9,307 customers in the data set, and 3,507,550 observations comprising daily information on customer engagement and purchases spanning two years (May 2015 - May 2017).

\section{Model specification}

\subsection{Key variables}

Dependent variables: There are two dependent variables in this study. The first dependent variable--Engagement $_{i t^{--}}$is a dummy of whether customer $\mathrm{i}$ interacted with the fan page on day t. We use this dependent variable for testing Hypothesis 1. The second dependent variable--- Purchase $_{i t^{---}}$is a dummy for whether customer i made a purchase on day $t$. We use this dependent variable for testing Hypothesis 2 .

Independent variables: Our explanatory variable is the interaction term After ${ }_{t} \times$ TreatmentGroup $_{i}$, where After $_{t}$ is a dummy for whether day $t$ is after the introduction of the fan page store and TreatmentGroup $i$ is a dummy for whether customer $i$ is in Shenzhen where people have access to the fan page store. Table 1 summarizes the definitions of our key variables, and Table 2 presents summary statistics.

Table 1. Summary for the key variables

\begin{tabular}{|c|c|}
\hline Key Variables & Description \\
\hline \multicolumn{2}{|c|}{ Dependent Variables: } \\
\hline Engagement $_{i t}$ & $\begin{array}{l}\text { A dummy for whether customer i engaged } \\
\text { with the fan page on day } t\end{array}$ \\
\hline Purchase $_{i t}$ & $\begin{array}{l}\text { A dummy for whether customer i made a } \\
\text { purchase on day } t\end{array}$ \\
\hline \multicolumn{2}{|c|}{ Explanatory Variables: } \\
\hline $\begin{array}{l}\text { After } \times \text { Treatm } \\
\text { entGroup }\end{array}$ & $\begin{array}{l}\text { After } r_{t} \text { is a dummy for whether day } \mathrm{t} \text { is after } \\
\text { the introduction of the fan page store, and } \\
\text { TreatmentGroup is a dummy for whether } \\
\text { customer i is in Shenzhen }\end{array}$ \\
\hline \multicolumn{2}{|c|}{ Control Variables: } \\
\hline UnitPrice $_{i t}$ & $\begin{array}{l}\text { A measure for the average discount for all } \\
\text { products on day } t \text { in the city that individual } \\
i \text { is located; }\end{array}$ \\
\hline
\end{tabular}


Table 2. Summary statistics for the key variables

\begin{tabular}{|c|c|c|c|c|c|}
\hline Variable & Obs & Mean & Std. Dev. & Min & Max \\
\hline Engagement ${ }_{i t}$ & 3507550 & 0.03 & 0.16 & 0 & 1 \\
\hline Purchase $_{i t}$ & 3507550 & 0.02 & 0.14 & 0 & 1 \\
\hline $\begin{array}{l}\text { After }_{t} \\
\text { TreatmentGr }\end{array}$ & 3507550 & 0.57 & 0.49 & 0 & 1 \\
\hline $\begin{array}{l}\text { oup }_{i} \\
\text { After } \\
\times \text { Treatment }^{\text {Treat }}\end{array}$ & 3507550 & 0.59 & 0.49 & 0 & 1 \\
\hline Group $_{i}$ & 3507550 & 0.33 & 0.47 & 0 & 1 \\
\hline UnitPrice & 3507550 & 0.64 & 0.23 & 0 & 1 \\
\hline
\end{tabular}

\subsection{Identification strategy}

To identify the impact of introducing a fan page store on customer engagement with the fan page and purchases, we need to address several potential endogeneity concerns to our identification strategy.

-Unobserved time-invariant heterogeneity. For example, there could be across-brand heterogeneity in customer preferences. Besides, there could also be across-individual heterogeneity in customer preferences of engagement and purchases. Not accounting for the heterogeneity across brands and across individuals could bias our estimation. We thus use individual-fixed effect in the main models for unobservable time-invariant heterogeneity.

-Unobserved time-variant heterogeneity. For example, time-related factors may affect both the dependent variables and the independent variables. Specifically, the timing of sale promotions and seasonality can be correlated with the introduction of the fan page store as well as customer engagement and purchases. However, sale promotions and seasonality is usually hard to objectively measure. Not including sale promotions and seasonality in our model could bias our estimation. Thus, we use time-fixed effect to control for time specific shocks experienced by all customers.

-Reverse causality. Reverse causality is less problematic in this study, as the treated city is selected in a way random to customer future engagement and purchases. By doing so, customer future engagement and purchases cannot be the antecedent of the retailer's decision of introducing a store section on the fan page.

- Validity of the field experiment design. An ideal field experiment requires everything else (except the introduction of the treatment) to be exactly the same for the control and treatment group. Though our field experiment may still suffer from the possibility of contamination caused by uncontrollable factors such as weather and local economy, we tried our best to maintain the experimental conditions. For example, a senior manager in the fashion retailer confirms that the introduction of the fan page store is exogenous to the posting content on the fan pages, and that all other settings (expect introducing a fan page store) on the fan page are exactly the same for customers in both the control and treatment cities. More specifically, customers in both cities can receive the same post, at the same time, during the whole period of observation. Such technique undermines the issue of omitted variable bias that may be caused by a simultaneous change in the retailer's posting strategy on the fan page.

\subsection{Model specification}

We first estimate the effect of the introduction of a fan page store on customer engagement with the fan pages using Equation (1). To account for potential price change correlated with engagement and our explanatory variable, we include UnitPrice $_{i t}$ (the average discount for all products on day $t$ in the city that individual $i$ is located) as a control. As the dependent variable is a dummy and the variables of interest include interaction terms, we estimate our baseline model using Linear Probability Model (LPM). The advantage of LPM compared to non-linear probability model (NPM) is that the coefficient of an interaction term in the LPM can be easily estimated and interpreted, while the magnitude of the engagement effect in nonlinear models does not equal the marginal effect of the interaction term (can be of opposite sign) and its statistical significance is not calculated by standard software [1]. Considering that LPM generally provides consistent estimations with those of NPM, we use LPM as the main model as suggested by the literature and use NPM as a robustness check. However, it is important to note that LPM has a drawback that it can produce negative probabilities or probabilities greater than one. This drawback requires additional consideration and complementary analysis when interpreting the LPM estimations.

$$
\begin{gathered}
P\left(\text { Engagement }_{i t}=1 \mid x\right)=\beta_{0}+\beta_{1} \text { After }_{t} \times \\
\text { TreatmentGroup }_{i}+\beta_{2} \text { UnitPrice }_{i t}+ \\
H^{\prime} \eta_{1}+R^{\prime} \chi_{1}+\varepsilon_{i t}
\end{gathered}
$$

where Engagement ${ }_{i t}$ indicates whether individual $i$ interacted with the fan page on day $t . \mathrm{H}$ is the vector of individual fixed effects, $\mathrm{R}$ is the vector of time dummies, and $\varepsilon$ indicates the error term. To reduce heteroscedasticity concerns, we used robust standard errors clustered at the individual level.

Next, we estimate the effect of the fan page store on customer purchase using Equation (2). To account 
for potential price change correlated with purchase and our explanatory variable, we include UnitPrice $_{i t}$ (the average discount for all products on day $t$ in the city that individual $i$ is located).

$$
\begin{gathered}
. P\left(\text { Purchase }_{i t}=1 \mid x\right)=\beta_{0}+\beta_{1} \text { After }_{t} \times \\
\text { TreatmentGroup }_{i}+\beta_{2} \text { UnitPrice }_{i t}+ \\
H^{\prime} \eta_{1}+R^{\prime} \chi_{1}+\varepsilon_{i t}
\end{gathered}
$$

where Purchase $_{i t}$ indicates whether individual $i$ made any purchase on day $t . \mathrm{H}$ is the vector of individual fixed effects, $\mathrm{R}$ is the vector of time dummies, and $\varepsilon$ indicates the error term. To reduce heteroscedasticity concerns, we used robust standard errors clustered at the individual level.

\subsection{Results}

Results of Equation 1 and 2 are presented in Table 3. Column 1 in Table 3 shows the estimation of the Equation 1. The results show a significantly negative coefficient of After $\times$ TreatmentGroup, which means that customers are less likely to interact with the fan page after the introduction of the fan page store. The results indicate that the introduction of the "store" decreases customers' likelihood to interact with the fan pages by $0.744 \%$ from a baseline of $2.88 \%$. This translates to a $26 \%$ decrease in customer engagement with the fan page. Thus, our Hypothesis 1 is supported.

Column 2 in Table 3 shows the estimation of the Equation 2. The results show a significantly negative coefficient of After $\times$ TreatmentGroup, which means that customers in the treated city are less likely to make purchase after the introduction of the fan page store. The results indicate that the introduction of the "store" decreases customers' likelihood to make purchase by $4.58 \%$, translating to a $4.6 \%$ decrease in sales. Hence, our Hypothesis 2 is supported.

Table 3. Empirical results (LPM)

\begin{tabular}{lcc}
\hline VARIABLES & $(1)$ & $(2)$ \\
Engagement & Purchase \\
\hline After $\times$ TreatmentGroup & $-0.00744^{* * *}$ & $-0.0458^{* * * *}$ \\
& $(0.00208)$ & $(0.00168)$ \\
UnitPrice & $0.0138^{* * *}$ & $-0.00995^{* * *}$ \\
& $(0.00343)$ & $(0.00249)$ \\
Constant & $0.313^{* * *}$ & $0.202^{* * *}$ \\
& $(0.0121)$ & $(0.0119)$ \\
& & \\
Observations & $3,507,550$ & $3,507,550$ \\
R-squared & 0.009 & 0.011 \\
Number of customers & 9,307 & 9,307 \\
Individual effect & Fixed & Fixed \\
Time Effect & Fixed & Fixed \\
\hline \multicolumn{2}{c}{ Robust standard errors in parentheses } \\
$* * * \mathrm{p}<0.01, * * \mathrm{p}<0.05, * \mathrm{p}<0.1$
\end{tabular}

\subsection{Robustness checks}

Our findings rely on several identifying assumptions, which we address with additional empirical tests.

\subsubsection{An alternative measure for customer engagement}

In the main analysis, we use a dummy Engagement $_{i t}$ to indicate customers' propensity to engage with the fan page. For the robustness of the analysis, we replicate our Equation (1) with an alternative dependent variable---LnNoOfEngagement ${ }_{i t}$, a measure for the log-formed total number of interactions customer $\mathrm{i}$ made with the fan page on day $\mathrm{t}$. Results are exhibited the Column 2 in Table 3. The coefficient of After $\times$ TreatmentGroup is still significantly negative, therefore supporting our Hypothesis 1.

Table 4. Empirical results with an alternative measure for engagement

\begin{tabular}{lcc}
\hline \multirow{2}{*}{ VARIABLES } & $(1)$ & $(2)$ \\
Engagement & LnNoOfEngagementit \\
After $\times$ TreatmentGroup & $-0.0074 * * *$ & $-0.00743^{* * *}$ \\
& $(0.00208)$ & $(0.00238)$ \\
UnitPrice & $0.0138^{* * *}$ & $0.0122 * * *$ \\
& $(0.00343)$ & $(0.00392)$ \\
Constant & $0.313 * * *$ & $0.419 * * *$ \\
& $(0.0121)$ & $(0.0197)$ \\
Observations & $3,507,550$ & $3,507,550$ \\
R-squared & 0.009 & 0.011 \\
Number of customers & 9,307 & 9,307 \\
Individual effect & Fixed & Fixed \\
Time Effect & Fixed & Fixed \\
\hline \multicolumn{2}{c}{ Robust standard errors in parentheses } \\
\multicolumn{2}{c}{$* * * \mathrm{p}<0.01, * * \mathrm{p}<0.05, * \mathrm{p}<0.1$}
\end{tabular}

\subsubsection{Justification of the parallel trend assumption}

We validated the Difference-in-Difference estimation that requires a parallel trend assumption. That is, in the absence of the introduction of the fan page store, ex-ante characteristics of the treatment group should be similar to the ex-ante characteristics of the control group. To test this parallel trend assumption, we used the relative time model [14] as a robustness check. Specifically, we added a series of dummies for all weeks and the interactions between the week dummies and the treatment dummy. The coefficients of the interaction terms capture potential pre-treatment differences. If the results of the relative time model show that the gap between the characteristics of the 
treatment group and the control group before the rule change was not significantly different compared to that of the baseline period, it would provide evidence that the trend of ex-ante characteristics of the treatment group kept parallel to that of the control group. However, if our results of the relative time model show that the gap between the characteristics of the treatment group and the control group significantly changed after the introduction of the fan page store, it would provide evidence that the introduction of the fan page store affected the treatment group relative to the control group.

Indeed, our results support the parallel trend assumption between the treatment group and control group before the introduction of the fan page store. Also, we observe that customer engagement and purchases of individuals in the treatment group decreased significantly relative to that of the control group after the introduction of the fan page store. Taken together, these findings support the parallel trend assumption for our Difference-in-Difference model.

\section{Main findings, limitations and contributions}

Recent years have witnessed an explosion in commercialization of social media as a means for firms to connect with consumers and expand revenue streams. The abundant information on social media enables firms to grow insights into customer behavior, understand their own business drivers, and design more targeted marketing strategies. All such benefits make social network a promising marketing land. However, an intense debate rages over whether firms should actively reach customers on social media for commercial purposes. To our best knowledge, this study represents the first empirical efforts that assess and quantify the impact of introducing a store on social media fan pages, a novel practice for firms to reach social media users. Utilizing data from a field experiment, our study finds that merely introducing a store on fan pages may not be welcomed by social media users, and it could reduce customer engagement with the fan pages and decrease sales.

Our study has certain limitations, some of which can pave the way for future research in this area. Firstly, our estimation depends on the study's context. The retailer mainly sells shoes, a type of experience goods. Accordingly, practitioners should be careful when generalizing our findings to other product types, such as products with lower purchase frequency (e.g., cars) and standardized search products (e.g., books), since customers may have a different preference for fan page stores across product types [4, 11, 18]. Secondly, since the retailer in our study sells shoes, it mainly relies on the offline retailer channel. Therefore, generalizing our finding to firms mainly relying on the online retail channel must be done with caution. However, we believe that our theoretical arguments and hence the results are likely to hold in other contexts. Thirdly, we focus on engagement/purchase from social media users who have enrolled in a loyalty program, but are unable to capture the potential spillovers from loyalty members to non-loyalty members. Future work should explore these dynamics further, and explicitly consider spillovers among social media users throughout their social network.

Our study contributes to academic literature. First, although researchers have been discussing the topic of business value of social media in the last decade [3, 23, 30], little research has examined the impact of introducing a store on fan pages. From this aspect, our work discusses a novel practice marketers can use on their social media fan pages, and our finding contributes to the knowledge of the business value of social media. Secondly, though some scholars have noticed the potential drawbacks of overcommercializing social media $[18,38]$, our approach is different from the extant survey and interview studies that we use actual behavioral data to establish the causal link between fan page stores and consumer behaviors, in terms of both a customer's propensity to engage with fan pages and make purchases. Our findings empirically show that merely introducing a store on fan pages would decrease customer engagement and purchases. Finally, our study implicates the boundary regulation theory in the Information System (IS) field, and contributing to the IS literature by uncovering the role of function alignment in users' technology acceptance decisions.

This work has implications for practitioners. Prima facie, the commercialization of social media appears to be a win-win solution. For social media platforms, it essentially provides a way to monetize the platforms. For example, Facebook alone generated 26.89 billion U.S. dollars in ad revenues in 2016. For firms, social media opened the door to deeper interest and behavioral targeting. Ideally, opening fan page stores should be able to help firms reach potential buyers and effectively transit firms' connection with customers on social media into profits. But, our finding indicates that social media users may not like to see pure selling activities on their social space, since pure selling could conflict with their definition of boundary on social media. Our study indicates that pure selling may hurt firms, not only through decreasing customer engagement but also reducing sales. Such findings 
highlight the need for caution when firms push business toward social media.

\section{References}

[1] Ai, C. and Norton, E. C., "Interaction terms in logit and probit models", Economics Letters, 2003, 123-129.

[2] Aral, S., Dellarocas, C., and Godes, D., "Introduction to the special issue- social media and business transformation: a framework for research", Information Systems Research, 2013, 3-13.

[3] Armelini, G. and Villanueva, J., "Adding social media to the marketing mix", IESE Insight, 2011, 29-36.

[4] Assmus, G., Farley, J. U., and Lehmann, D. R., "How advertising affects sales: Meta-analysis of econometric results", Journal of Marketing Research, 1984, 65-74.

[5] Calder, B. J. and Malthouse, E. C., "Media engagement and advertising effectiveness", Kellogg on Advertising and Media, 2008, 1-36.

[6] De Vries, L., Gensler, S., and Leeflang, P. S., "Popularity of brand posts on brand fan pages: An investigation of the effects of social media marketing", Journal of Interactive Marketing, 2012, 83-91.

[7] De Vries, N. J. and Carlson, J., "Examining the drivers and brand performance implications of customer engagement with brands in the social media environment", Journal of Brand Management, 2014, 495-515.

[8] Ehrenberg, A. S., "Repetitive advertising and the consumer", Journal of Advertising Research, 2000, 39-48.

[9] Epstein, R. S., Keeping boundaries: Maintaining safety and integrity in the psychotherapeutic process, American Psychiatric Pub, 1994.

[10] Fournier, S. and Avery, J., "The uninvited brand", Business Horizons, 2011, 193-207.

[11] Gallaugher, J. and Ransbotham, S., "Social media and customer dialog management at Starbucks", MIS Quarterly Executive, 2010.

[12] Goldfarb, A. and Tucker, C., "Online display advertising: Targeting and obtrusiveness", Marketing Science, 2011, 389404.

[13] Granados, N. F., Gupta, A. and Kauffman, R. J., "The impact of IT on market information and transparency: A unified theoretical framework", Journal of the Association for Information Systems, 2006, 7.

[14] Greenwood, B. N. and Wattal, S., "Show me the way to go home: An empirical investigation of ride sharing and alcohol related motor vehicle homicide", Management Science, 2016.

[15] $\mathrm{Gu}, \mathrm{B}$. and Ye, Q., "First step in social media: Measuring the influence of online management responses on customer satisfaction", Production and Operations Management, 2014, 570-582.

[16] Heller Baird, C. and Parasnis, G., "From social media to social customer relationship management", Strategy \& Leadership, 2011, 30-37.

[17] Hollebeek, L. D., Glynn, M. S., and Brodie, R. J., "Consumer brand engagement in social media: Conceptualization, scale development and validation", Journal of Interactive Marketing, 2014, 149-165.
[18] Hutter, K., Hautz, J., Dennhardt, S., and Füller, J., "The impact of user interactions in social media on brand awareness and purchase intention: the case of MINI on Facebook", Journal of Product \& Brand Management, 2013, 342-351.

[19] Jansen, B. J., Zhang, M., Sobel, K., and Chowdury, A., "Twitter power: Tweets as electronic word of mouth", Journal of the Association for Information Science and Technology, 2009, 2169-2188.

[20] Jones, J. P., When ads work: New proof that advertising triggers sales, ME Sharpe, 2006.

[21] Kaplan, A. M. and Haenlein, M., "Users of the world, unite! The challenges and opportunities of Social Media", Business Horizons, 2010, 59-68.

[22] Karr-Wisniewski, P., Wilson, D. and Richter-Lipford, H. A new social order: Mechanisms for social network site boundary regulation. City, 2011.

[23] Kietzmann, J. H., Hermkens, K., McCarthy, I. P. and Silvestre, B. S., "Social media? Get serious! Understanding the functional building blocks of social media", Business Horizons, 2011, 241-251.

[24] Kim, A. J. and Ko, E., "Do social media marketing activities enhance customer equity? An empirical study of luxury fashion brand", Journal of Business Research, 2012, 1480-1486.

[25] Laroche, M., Habibi, M. R. and Richard, M.-O., "To be or not to be in social media: How brand loyalty is affected by social media?", International Journal of Information Management, 2013, 76-82.

[26] Lee, D., Hosanagar, K., and Nair, H. S., "The effect of social media marketing content on consumer engagement: Evidence from Facebook" , Stanford Graduate School of Business, 2014

[27] Markopoulos, P. M., Aron, R., and Ungar, L. H., "Product Information Websites: Are They Good for Consumers?", Journal of Management Information Systems, 2016, 624-651.

[28] Markopoulos, P. M. and Clemons, E. K., "Reducing buyers' uncertainty about taste-related product attributes", Journal of Management Information Systems, 2013, 269-299. [29] Markopoulos, P. M. and Kephart, J. O. "How valuable are shopbots?", ACM, 2002.

[30] Marsden, P., Social Commerce, GRIN Publishing, 2010. [31] Muntinga, D. G., Moorman, M., and Smit, E. G., "Introducing COBRAs: Exploring motivations for brandrelated social media use", International Journal of advertising, 2011, 13-46.

[32] Ray, M. L., Sawyer, A. G., Rothschild, M. L., Heeler, R. M., Strong, E. C., and Reed, J. B., "Marketing communication and the hierarchy-of-effects", 1973.

[33] Rishika, R., Kumar, A., Janakiraman, R., and Bezawada, R., "The effect of customers' social media participation on customer visit frequency and profitability: an empirical investigation", Information Systems Research, 2013, 108-127. [34] Sashi, C., "Customer engagement, buyer-seller relationships, and social media", Management Decision, 2012, 253-272.

[35] Stelzner, M. A., "Social media marketing industry report", Social Media Examiner, 2011, 1-10. 
[36] Stutzman, F. and Hartzog, W. "Boundary regulation in social media", ACM, 2012.

[37] Tang, Q., Gu, B., and Whinston, A. B., "Content contribution for revenue sharing and reputation in social media: A dynamic structural model", Journal of Management Information Systems, 2012, 41-76.

[38] Taylor, D. G., Lewin, J. E., and Strutton, D., "Friends, fans, and followers: do ads work on social networks?", Journal of Advertising Research, 2011, 258-275.

[39] Tuten, T. L. and Solomon, M. R., Social Media Marketing, Sage, 2014.

[40] Wisniewski, P., Lipford, H., and Wilson, D, "Fighting for my space: Coping mechanisms for SNS boundary regulation", ACM, 2012. 